\title{
CONDUCTOR DESIGN FOR THE VLHC TRANSMISSION LINE MAGNET
}

\author{
G.W. Foster", V. Kashikhin, M. McAshan, P.O. Mazur, H. Piekarz, J. T. Volk, R. Walker \\ FNAL, Batavia, IL
}

\section{Abstract}

The transmission line magnet [1] is under development for the Very Large Hadron Collider (VLHC) at Fermilab with the expectation that it's cost will be several times less (per Tesla-meter) than conventional superconducting magnets. It is a dual-aperture warm-iron superferric magnet built around an 80kA superconducting transmission line. The superconductor consists of 8 Rutherford (SSC Outer) cables in an Invar pipe jacket. The conductor design requirements and development program is described. A 100kA conductor test facility based on inductive coupling is described.

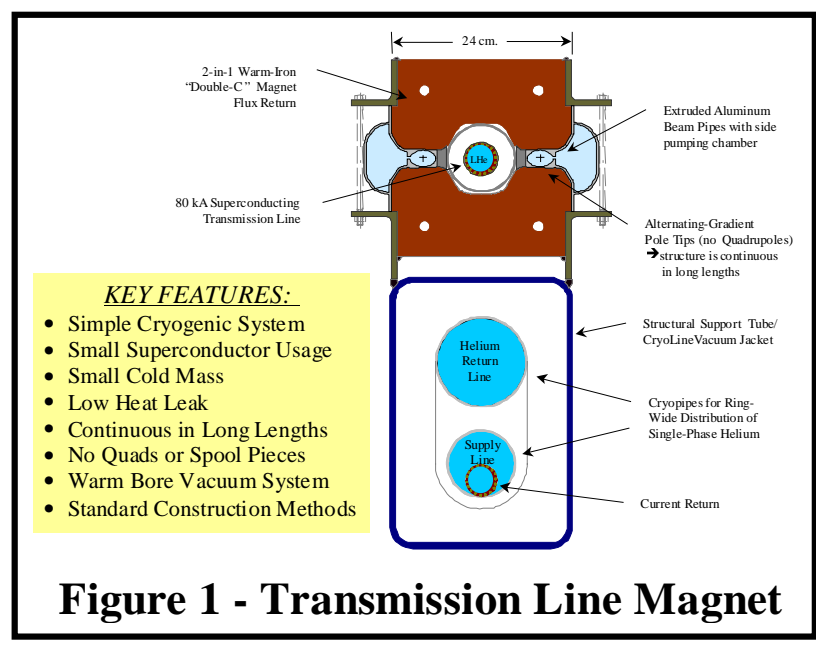

\section{INTRODUCTION}

When one examines the traditional cost drivers of superconducting magnets (cold mass, magnetic stored energy, superconductor usage, cryogenic heat load, etc.) the transmission line magnet (Figs. 1-2) enjoys a significant advantage over conventional designs. The simplicity of the design (low inductance single turn magnet, all-piping cryogenic system, absence of quadrupoles or complicated magnet ends, and a warm bore vacuum system which is not sensitive to synchrotron radiation) offers many advantages for large hadron accelerators. For these reasons it is being developed as an affordable magnet for the VLHC[2], a $100 \mathrm{TeV} \mathrm{E}_{\mathrm{CM}}$ proton-proton collider under development for Fermilab. The parameters of the magnet are given in Table 1.

"Work supported by the URA under contract to the US DoE.

\#Email: gwf@fnal.gov
Table 1: Transmission Line Magnet Parameters

\begin{tabular}{|l|l|}
\hline Magnet Type & Warm Iron, Warm Bore \\
\hline Magnet Topology & Double-C, 2-in-1 \\
\hline Operating Range & $0.1 \mathrm{~T} \rightarrow 2 \mathrm{~T}$ \\
\hline Drive Conductor & $\begin{array}{l}\text { Single turn, 80 kA Super- } \\
\text { conducting Transmission line }\end{array}$ \\
\hline Focusing & $\begin{array}{l}\text { Combined Function } \\
\text { (no quads or spool pieces) }\end{array}$ \\
\hline Normalized Gradient & $3 \% / \mathrm{cm}$ \\
\hline Magnet Gap & $3 \mathrm{~cm} \times 2 \mathrm{~cm}(\mathrm{H} \times \mathrm{V})$ \\
\hline $\begin{array}{l}\text { Good-Field Aperture } \\
\left(\mid \delta \mathrm{B} / \text { Bo } /<10^{-4}\right)\end{array}$ & $\begin{array}{l}2 \mathrm{~cm} \text { round at injection } \\
1 \mathrm{~cm} \text { round at 2T }\end{array}$ \\
\hline Iron Yoke & $\begin{array}{l}22 \mathrm{~cm} \times 24 \mathrm{~cm}(\mathrm{H} \times \mathrm{V}) \\
\text { Laminated Low-carbon Steel }\end{array}$ \\
\hline Transmission Line & $\begin{array}{l}\text { Cryopipe: 4cm OD } \\
\text { Vacuum Jacket: 7.5cm OD }\end{array}$ \\
\hline Inductance & $\begin{array}{l}2.8 \mathrm{uH} / \mathrm{m} \text { (low currents) } \\
2.2 \mathrm{uH} / \mathrm{m}\left(2 \mathrm{E}_{\mathrm{S}} / \mathrm{I}^{2} \text { at } 75 \mathrm{kA}\right)\end{array}$ \\
\hline
\end{tabular}

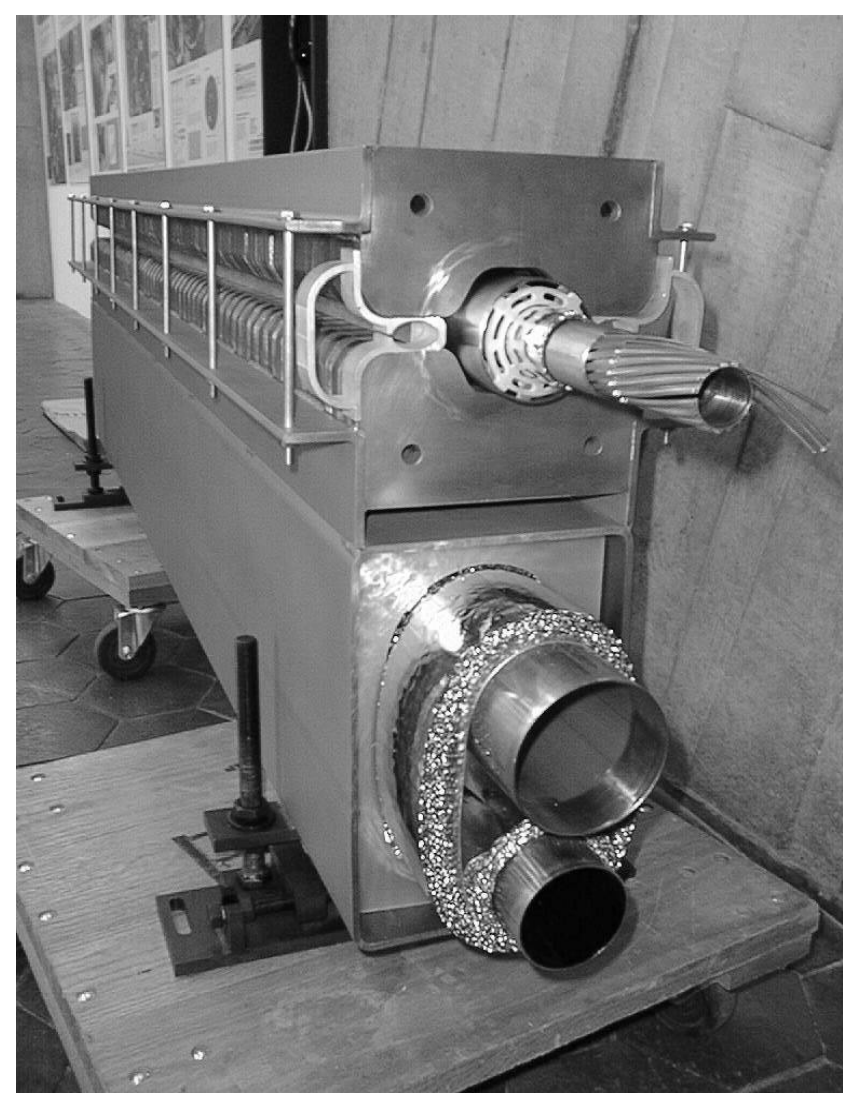

Fig. 2 - Transmission line magnet. 


\section{SUPERCONDUCTING CABLE DESIGN}

The major cryogenic component of the transmission line magnet is the 80kA superconducting DC transmission line (fig. 3) that energizes the magnet. The conductor requirements are similar to a cable-in-conduit design with the following exceptions:

- Accurate positioning $( \pm 0.5 \mathrm{~mm})$ of the conductor must be maintained inside the iron yoke to limit magnetic decentering forces. To meet this requirement the superconductor is evenly spaced along the inner circumference of the cold pipe. This configuration also minimizes the self-field of the conductor.

- A $3 \mathrm{~cm}$ clear bore must be maintained to allow helium transport over $4-5 \mathrm{~km}$. This requirement is met using a perforated Invar inner pipe around which conventional superconducting cables (leftover SSC outer coil cables) are spirally wrapped with a $\sim 1 \mathrm{~m}$ pitch. The cables are wrapped with copper tape and placed inside an Invar pipe jacket to contain the helium.

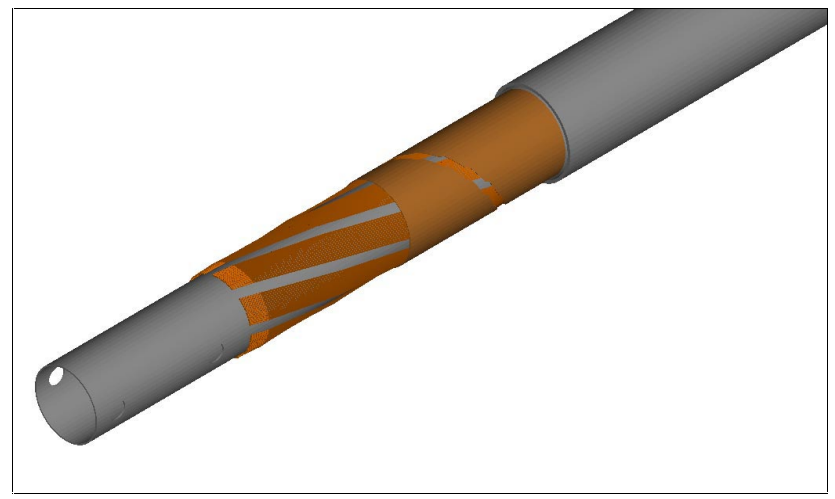

Fig. 3 - Transmission Line Conductor, including perforated Invar core, array of 8 Rutherford (SSC outer) cables, spiral wrapped copper tape (4 layers $x 0.25 \mathrm{~mm}$ ), and outer Invar pipe jacket $3.81 \mathrm{~cm}$ OD x $1.25 \mathrm{~mm}$ wall. After assembly the inner perforated core is expanded outwards by forcing an expanding plug through the core.

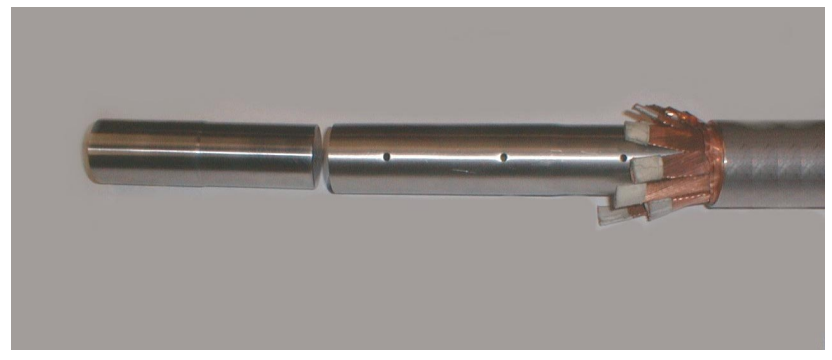

Fig. 4 - End of transmission line conductor. From right to left: Invar pipe jacket, superconducting cables, perforated Invar former, and expanding plug.

- It must operate with zero thermal contraction from $300 \mathrm{~K}$ to $5 \mathrm{~K}$. This is necessary since the conductor loops around the entire ring without bellows or expansion joints. This is accomplished with an Invar jacket and by taking advantage of the longitudinal stretchiness of the Rutherford-style superconducting cable which carries the current. To ensure reliability of the Invar cryopipe in the "zero-contraction" mode a testing program has been completed. In the test a 50 meter section of Invar pipe was cut into more than 125 pieces, re-welded together using automatic equipment, then thermal cycled 1000 times to between $300 \mathrm{~K}$ and $80 \mathrm{~K}$ with the ends constrained to prevent thermal contraction. After thermal cycling the pipe was checked and found to be free of leaks. The number of (welds $\mathrm{x}$ thermal cycles) in this test corresponds to 40 thermal cycles of the $3 \mathrm{TeV}$ injector to the VLHC.

- To survive quenching, it must contain enough copper and thermal mass to allow a current dump from 100kA with a 1 second time constant. This requires $\sim 1.5 \mathrm{~cm}^{2}$ of copper stabilizer in addition to the heat capacity of the helium and Invar piping.

- Field splices must be reasonably convenient for the conductor. A joint resistance of $\sim 0.1 \mathrm{n} \Omega$ (corresponding to $1 \mathrm{~W}$ power dissipation at $100 \mathrm{kA}$ ) is adequate. Figs. 5-6 show the techniques developed for the $100 \mathrm{kA}$ conductor test facility.

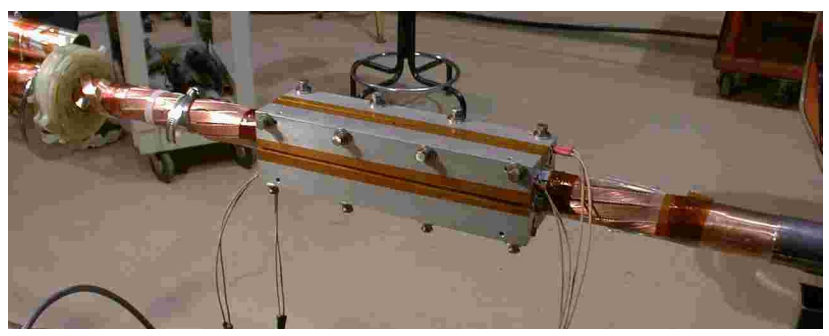

Fig 5 - Splicing technique for 100kA conductor test facility. Pre-tinned cables are interleaved and clamped in an aluminum 4-way split block with heating cartridges and temperature regulation.

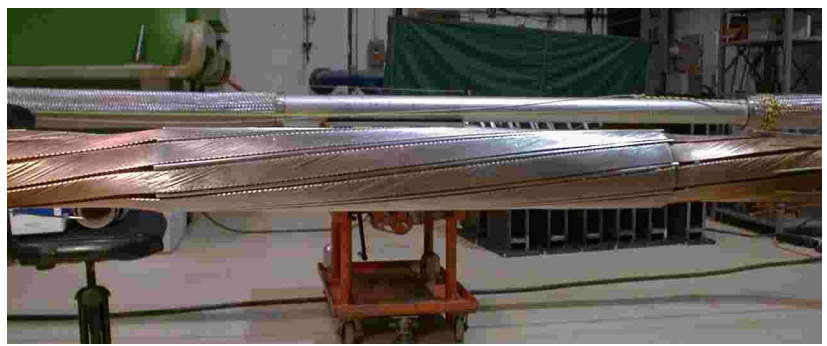

Fig. 6 - Completed splice for the conductor test loop. After soldering, the conductor is wrapped in copper tape to allow clamshell welding of the helium pipe over the splice. The vacuum jacket is made up with telescoping sections over the splice region.

\section{OPERATING TEMPERATURE}

The choice of operating temperature is a wellknown tradeoff between superconductor costs and highfield performance (which favor a low operating temperature) and cryogenic simplicity, capital and operating costs (which favor a high operating 
temperature). The trend in recent high field magnet designs is towards complicated $1.8 \mathrm{~K}$ cryogenic systems and/or expensive conductor. In contrast, costoptimization of the transmission line magnet resulted in conventional NbTi superconductor operating at $6.5 \mathrm{~K}$ and a very simple single-phase cryogenic system (fig.7). The system uses no recoolers or heat exchangers and has one remotely operated valve every $4 \mathrm{~km}$ of tunnel [3]. In contrast, high field magnet designs such as the LHC require $>1$ remotely operated valve per dipole.

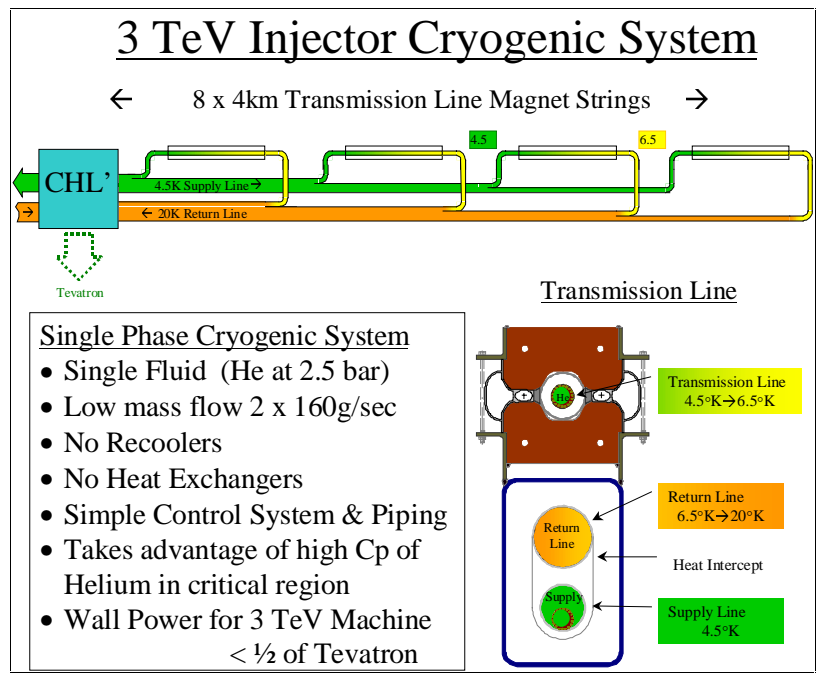

Fig. 7 - The cryogenic system of the transmission line magnets for the $3 \mathrm{TeV}$ injector to the VLHC. The higher energy machine duplicates this structure, with a cryogenic plant approximately every $40 \mathrm{~km}$ along the circumference.

Superconductor costs are only $5 \%(10 \%)$ of the total cost of the transmission line magnets at $4.5 \mathrm{~K}(6.5 \mathrm{k})$ operation. There are several reasons for this. The irondominated design requires fewer ampere-turns per Tesla than a conductor-dominated (cosine-theta) magnet. The conductor operates at a low field $(0.9 \mathrm{~T})$ so that a very high current density can be achieved. The transmission line magnet does not require the micron-sized filaments needed by $\cos \Theta$ magnets, which lowers processing costs. Finally, there has been almost an order-of-magnitude increase $^{[4]}$ in the current-carrying capability of $\mathrm{NbTi}$ conductors (at low field) since the time of the Tevatron.

\section{MAGNET TEST PROGRAM}

A 100kA test facility is under construction at Fermilab. This is a scale up of the successfully-operated test facility reported in [5]. To avoid the expense of 100kA current leads, the facility uses a floating superconducting loop and inductive coupling through a warm-iron transformer made from an old beamline magnet. The cryogenic system is Dewar-based and consists of a pressurized and pumped loop capable of operating at temperatures between $4.5 \mathrm{~K}$ and $\sim 10 \mathrm{~K}$. Initial tests to optimize various conductor designs [8] will use a $17 \mathrm{~m}$ loop containing a $4 \mathrm{~m}$ replaceable section of transmission line. The setup will then be used to power magnets of up to $50 \mathrm{~m}$ in length.

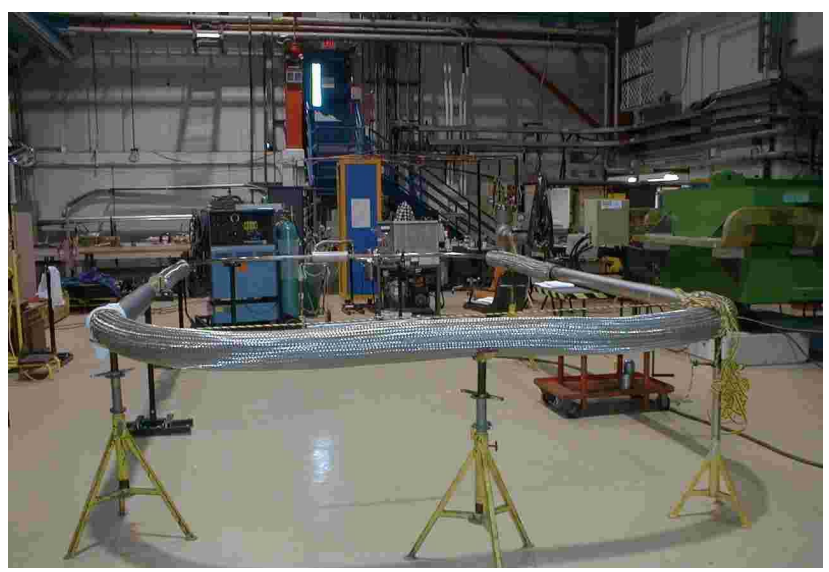

Fig. 9 - 100kA conductor test loop nearing completion. Dewar-based cryogenic system in background and drive transformer at right. The test loop contains a $4 \mathrm{~m}$ replaceable test section of transmission line

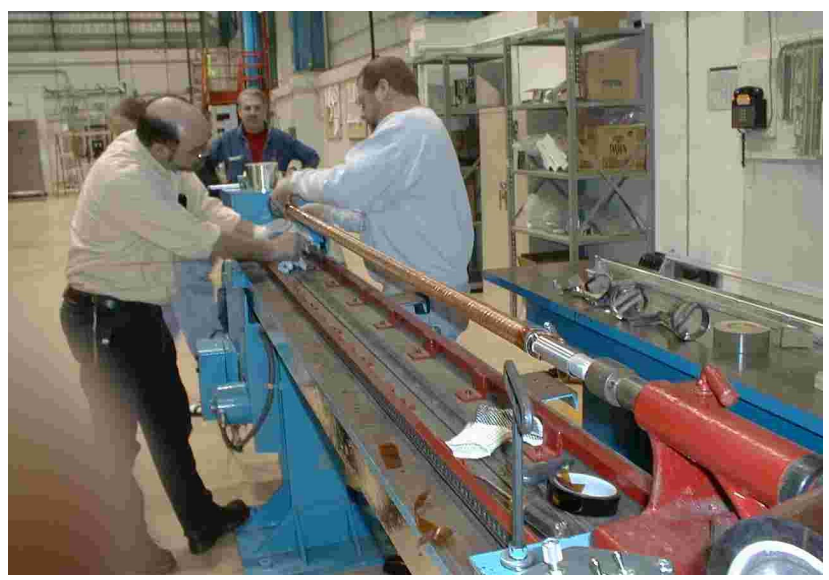

Fig. 10 - Spiral-wrapping of copper tape on prototype transmission line lengths using the wrapping machine used for Tevatron and Recycler beam pipes. The conductor design and swaging operation have been chosen to allow in-house production of $70 \mathrm{~m}$ lengths.

\section{REFERENCES}

[1] "Transmission Line Magnet Status Report", G.W. Foster, VLHC Information Packet for Gilman HEPAP Subpanel, Fermilab 1998. See also [2].

[2] VLHC Project information and technical documents can be found at WWW.VLHC.ORG

[3] "Cryogenic Design of the $3 \mathrm{TeV}$ Injector", $\mathrm{M}$. McAshan, ibid ref [1], [2].

[4] D. Larbelestier and P. J. Lee, "New Developments in Niobium Titanium Superconductors", PAC'95.

[5] "Design \& Operation of an Experimental Double-C Transmission Line Magnet", P.Mazur et. al, PAC 97

[6] E. Malamud et. al, PAC '99. 